OPEN ACCESS

Edited by:

Jun Sun

China University of Geosciences

Wuhan, China

Reviewed by:

Alfonso Corzo

University of Cadiz, Spain

Camila Fernandez,

UMR7621 Laboratoire

d'Océanographie Microbienne (LOMIC), France

*Correspondence:

Joaquin Ortiz

jortiz@geomar.de

Specialty section:

This article was submitted to

Marine Biogeochemistry,

a section of the journal

Frontiers in Marine Science

Received: 17 July 2021 Accepted: 07 December 2021

Published: 12 January 2022

Citation:

Ortiz J, Arístegui J, Taucher J and Riebesell U (2022) Artificial Upwelling

in Singular and Recurring Mode: Consequences for Net Community Production and Metabolic Balance.

Front. Mar. Sci. 8:743105.

doi: 10.3389/fmars.2021.743105

\section{Artificial Upwelling in Singular and Recurring Mode: Consequences for Net Community Production and Metabolic Balance}

\author{
Joaquin Ortiz ${ }^{1 *}$, Javier Arístegui ${ }^{2}$, Jan Taucher ${ }^{1}$ and Ulf Riebesell ${ }^{1}$ \\ 1 Marine Biogeochemistry, Biological Oceanography, GEOMAR Helmholtz Center for Ocean Research, Kiel, Germany, \\ ${ }^{2}$ Oceanografía Biológica, Instituto de Oceanografía y Cambio Global (IOCAG), Universidad de Las Palmas de Gran Canaria, \\ Las Palmas de Gran Canaria, Spain
}

Artificial upwelling of nutrient-rich waters and the corresponding boost in primary productivity harbor the potential to enhance marine fishery yields and strengthen the biological pump for sequestration of atmospheric $\mathrm{CO}_{2}$. There is increasing urgency to understand this technology as a "ocean-based solution" for counteracting two major challenges of the 21st century-climate change and overfishing. Yet, little is known about the actual efficacy and/or possible side effects of artificial upwelling. We conducted a large-scale off-shore mesocosm study $\left(\sim 44 \mathrm{~m}^{3}\right)$ in the oligotrophic waters of the Canary Islands to identify the community-level effects of artificial upwelling on a natural oligotrophic plankton community. Four upwelling intensities were simulated

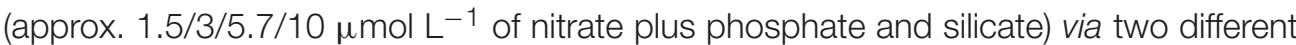
upwelling modes (a singular deep-water pulse vs. recurring supply every 4 days) for 37 days. Here we present results on the response of net community production (NCP), metabolic balance and phytoplankton community composition $(<250 \mu \mathrm{m})$. Higher upwelling intensities yielded higher cumulative NCP. Following upwelling onset, the phytoplankton community became dominated by diatoms in all treatments, but other taxa such as Coccolithophores increased later in the experiment. The magnitude of effects on the metabolic balance scaled with the amount of added deep water, leading to (i) a balanced to net-heterotrophic system in the singular and (ii) a net-autotrophic system in the recurring upwelling treatments. Accordingly, the mode in which nutrients are supplied to an oligotrophic system plays a crucial role in the ecosystem response, with recurring upwelling leading to higher long-term positive NCP than singular upwelling. These results highlight the importance of empirically measured local responses to upwelling such as community structure and metabolism, with major implications for the potential employment of artificial upwelling as an ocean-based solution to generate (primary) production.

Keywords: artificial upwelling, metabolic balance, primary production, net community production, mesocosm, CHEMTAX 


\section{INTRODUCTION}

Food security for a growing human population and climate change are two main global challenges of our time. The world population is projected to keep growing at least until the end of this century and the ensuing demand for food needs to be covered (United Nations, 2019). While food production on land shows some potential for sustainable improvement (Godfray et al., 2010), the oceans are already being exploited at, or even past, the limit of sustainability (Garcia and Rosenberg, 2010). Meanwhile, global agreements to mitigate the effects of anthropogenic climate change have been reached (UNFCC, 2015; Schellnhuber et al., 2016). But palpable actions still need to follow and it is clear that a mere reduction of emissions will not suffice (Lawrence et al., 2018). Yet most of the urgently needed technologies to actively remove $\mathrm{CO}_{2}$ from the atmosphere remain largely unexplored.

One approach that has been suggested to tackle both of these challenges at the same time is artificial upwelling. It has been proposed as a method to sustainably increase fisheries yield in unproductive areas of the ocean and potentially enhance carbon sequestration (Kirke, 2003; Lovelock and Rapley, 2007; GESAMP, 2019). However, the most essential prerequisite to achieve these goals is that the nutrients introduced via artificial upwelling fuel the growth of primary producers that subsequently increase productivity on higher trophic levels up to harvestable fish. Experimental data focusing on the effects of artificial upwelling are scarce. Several authors have found that artificial upwelling in oligotrophic waters can lead to (i) increased primary productivity (PP) and phytoplankton biomass, (ii) higher abundance of diatoms, (iii) a community succession from picophytoplankton to larger nano- and microphytoplankton as well as a (iv) shift from a balanced or net heterotrophic ecosystem to a net autotrophic one (McAndrew et al., 2007; Giraud et al., 2016; Casareto et al., 2017). But most of these data stem from small scale bottle fertilization experiments, making it difficult to extrapolate these finding to the community and ecosystem level. Maruyama et al. (2011) induced artificial upwelling in the open water through a perpetual salt fountain but only provided data on Chla, which increased significantly. The only open water study that included effects on the phytoplankton community was conducted by Masuda et al. (2010), who pumped up water from $205 \mathrm{~m}$ depth, discharged it at $20 \mathrm{~m}$ mixed with water from $5 \mathrm{~m}$ and tracked changes in nutrient concentrations, phytoplankton composition and growth for $63.9 \mathrm{~h}$. Other previous mesocosm studies included the addition of inorganic nutrients or nutrient rich deep water, but also further manipulations like artificially elevated $\mathrm{CO} 2$ concentration (Riebesell et al., 2013b; Taucher et al., 2017). This made it difficult to study exclusively the effects of the deep-water addition on the community.

Here we present results from an in situ mesocosm experiment in which we examined how a natural plankton community responds to artificial upwelling applied on a much larger, unprecedented scale under close to natural conditions. The main objective of the entire experiment was to assess the effectiveness and potential side effects of artificial upwelling as a technology to enhance marine food production and/or $\mathrm{CO}_{2}$ sequestration, so that better judgments can be made regarding its applicability on a larger spatial and temporal scale. This was achieved comparing different temporal frequencies and intensities of artificial upwelling through a multitude of parameters. The specific objective of this study was to evaluate its effects on net community production (NCP) and metabolic state of an oligotrophic community that is not adapted to more than occasional nutrient inputs. Based on this, we explore whether the response of the phytoplankton community could lead to the establishment of a solid foundation of primary producers needed to fuel a productive food web.

\section{MATERIALS AND METHODS}

\section{Experimental Setup}

The Canary Islands are a suitable place to test artificial upwelling: the subtropical oligotrophic waters display an overall year-round rather low PP ( $\sim 100-400 \mathrm{mg} \mathrm{C} \mathrm{m}^{-2} \mathrm{~d}^{-1}$, Arístegui et al., 2001). A bay located on the east coast of the island of Gran Canaria was chosen as the deployment site for the nine KOSMOS (Kiel Offshore Mesocosms for Ocean Simulations) units, laying protected from the most common swell and wind patterns (Gando Bay, $27.9279^{\circ} \mathrm{N}, 15.3654^{\circ} \mathrm{W}$ ). Transparent plastic roofs served as protection from precipitation and bird droppings. Technical details of the infrastructure are specified in Riebesell et al. (2013a). After a 7-day period of open water exchange the mesocosms were closed by lifting the top end out of the water and attaching the sediment traps to the bottom. A net $(3 \mathrm{~mm}$ mesh size) was pulled from bottom to top right after closure to exclude unevenly distributed large organisms from the enclosures. Total length of the mesocosm bags was $13 \mathrm{~m}$ plus an additional $2.7 \mathrm{~m}$ for the sediment trap, hereby enclosing a mean water volume of $43.78 \pm 1.35 \mathrm{~m}^{3}$ (Table 1).

To obtain suitable deep water (DW) an electric pump was deployed from a ship (RRS James Cook (United Kingdom) and $\mathrm{J}$ Socas (ES); between $28^{\circ} 00^{\prime} \mathrm{N}, 15^{\circ} 18^{\prime} \mathrm{E}$ and $27^{\circ} 57^{\prime} \mathrm{N}$, $\left.15^{\circ} 10^{\prime} \mathrm{E}\right)$ to $330 \mathrm{~m}$ depth. The water was pumped into a custom built DW collector bag $\left(\sim 100 \mathrm{~m}^{3}\right.$ capacity) and towed to the mesocosm site (for technical specifications see Taucher et al., 2017). Due to technical constraints the intended pumping depth of $\sim 600 \mathrm{~m}$ could not be reached. Therefore, collected DW was spiked with additional nutrients $\left(\mathrm{NO}_{3}, \mathrm{PO}_{4}\right.$ and $\mathrm{Si}$ as sodium nitrate, disodium phosphate and sodium silicate) to adjust the stoichiometry to the intended pumping depth. Nutrient concentrations were measured and adjusted routinely before each addition to the mesocosms. During the 39 days of the experiment, mesocosms were cleaned regularly on the inside and outside (for details on all activities see Supplementary Figure 1). Depth-integrated water samplers (IWS, Hydro-Bios, Kiel) were used to sample the entire water column $(0-13 \mathrm{~m})$ of each mesocosm every other day. The water column outside of the mesocosms at the mooring site was also sampled ("Atlantic") as an additional comparison for inorganic nutrients and photosynthetic pigments. In this paper we focus on PP measured through oxygen incubations. Inorganic nutrient concentrations are also provided and photosynthetic pigments were analyzed to 
TABLE 1 | Treatment overview with mesocosm volumes, total nutrients added and mean CR/GP/NCP rates with standard deviations for the duration of the study.

\begin{tabular}{|c|c|c|c|c|c|}
\hline Mesocosm & Treatment & $\begin{array}{l}\text { Total inorg. } \mathrm{N} \\
\text { added }\left[\mu \mathrm{mol} \mathrm{L} \mathrm{L}^{-1}\right]^{*}\end{array}$ & $\begin{array}{c}\text { Mean CR }{ }^{\star *} \\
{\left[\mu \mathrm{mol} \mathrm{O}_{2} \mathrm{~L}^{-1} \mathrm{~d}^{-1}\right]}\end{array}$ & $\begin{array}{c}\text { Mean GP** } \\
{\left[\mu \mathrm{mol} \mathrm{O}_{2} \mathrm{~L}^{-1} \mathrm{~d}^{-1}\right]}\end{array}$ & $\begin{array}{c}\text { Mean NCP } \mathrm{NC}^{\star *} \\
{\left[\mu \mathrm{mol} \mathrm{O} \mathrm{L}^{-1} \mathbf{d}^{-1}\right]}\end{array}$ \\
\hline 3 & Low singular & 1.61 & $3.24 \pm 0.44$ & $3.56 \pm 1.23$ & $0.31 \pm 0.98$ \\
\hline 2 & Low recurring & 1.54 & $3.48 \pm 0.82$ & $3.27 \pm 1.42$ & $-0.21 \pm 1.67$ \\
\hline 7 & Medium singular & 3.01 & $3.90 \pm 1.35$ & $5.57 \pm 5.04$ & $1.67 \pm 4.82$ \\
\hline 4 & Medium recurring & 3.06 & $4.38 \pm 0.84$ & $6.21 \pm 1.89$ & $1.84 \pm 1.6$ \\
\hline 6 & High recurring & 6.15 & $5.47 \pm 1.54$ & $9.57 \pm 4.14$ & $4.10 \pm 3.5$ \\
\hline 1 & Extreme singular & 9.82 & $8.92 \pm 4.05$ & $12.31 \pm 16.01$ & $3.39 \pm 15.33$ \\
\hline 8 & Extreme recurring & 12.26 & $9.50 \pm 3.24$ & $19.47 \pm 7.21$ & $9.97 \pm 5.8$ \\
\hline 5 & Control & 0.00 & $2.58 \pm 0.49$ & $3.09 \pm 0.58$ & $0.51 \pm 0.63$ \\
\hline
\end{tabular}

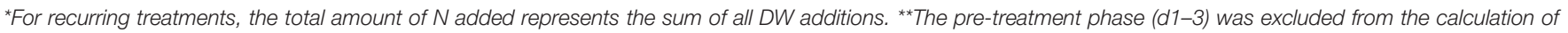
mean rates to better reflect treatment effects.

contribute additional information on the relative abundance of specific phytoplankton taxa.

\section{Treatment Details}

The experimental treatment consisted of one control mesocosm and two groups of four mesocosms subjected to either a singular (M1, M3, M7, M9; "singular") DW addition on day four (d4) or a total of eight DW additions every 4 days (M2, M4, M6, M8; "recurring") from d4 onward. An exception was $\mathrm{d} 21$, when DW addition was delayed by 1 day due to bad weather conditions. Within each group a gradient in upwelling intensity was established from "low" to "extreme" treatments, referring to the total amount of water volume replaced by DW (see Table 1). In accordance with upwelling intensity, respective singular and recurring upwelling treatments were intended to receive an equal total amount of inorganic nutrients e.g., low treatments should ideally receive the same total amount either at once (low singular) or throughout all eight additions (low recurring). The technical concept of the upwelling modes applied in this experiment roots in the design of potentially applicable pump types: stationary (moored) pumps would provide singular upwelling, as the fertilized water mass moves away with currents and winds; while free drifting pumps would provide continuous upwelling as they would move along with the water mass.

\section{Inorganic Nutrients}

Between $250-500 \mathrm{~mL}$ of water from the IWS, as well as from the DW bag, were subsampled into polypropylene bottles for analysis of inorganic nutrient concentrations $\left[\mathrm{NO}_{3}{ }^{-}, \mathrm{NO}_{2}{ }^{-}\right.$, $\left.\mathrm{NH}_{4}{ }^{+}, \mathrm{PO}_{4}{ }^{3-}, \mathrm{Si}(\mathrm{OH})_{4}\right]$. In the laboratories all nutrient samples were measured spectrophotometrically on a five channel Quaatro Autoanalyzer (Seal Analytical, Mequon, WI, United States) after being filtered through $0.45 \mu \mathrm{m}$ pore size glass fiber filters (Sterivex, Merck, Darmstadt, Germany).

Thanks to the intense monitoring of inorganic nutrients as well as dissolved and particulate organic $\mathrm{N}$ and $\mathrm{P}$ of both the water column and DW bag, it was possible to correct the inorganic nutrient concentrations in the water column to account for any $\mathrm{N}$ shifting to the dissolved and particulate organic nitrogen pool and inorganic nutrients lost in the removal of water before DW pumping. i.e., it was possible to factor in inorganic $\mathrm{N}$ previously added through the spiking of the DW that might have shifted to the organic $\mathrm{N}$ pool in the time elapsed until the actual addition. This allowed for accurate assessment of how much inorganic $\mathrm{N}$ was actually added. Since suspended particulate and dissolved organic nitrogen are not relevant nutrient sources for phytoplankton, henceforth " $\mu$ mol of nutrients" refers to total added inorganic nitrogen.

\section{Oxygen Production Rates}

Oxygen production as well as respiration rates were measured through 24-h incubations and the Winkler method, following recommendations from Carritt and Carpenter (1966), Bryan et al. (1976) and Grasshoff et al. (1999). Five liters of water were sampled from each treatment every second day and transported back to land in a cool box. Using a silicone tube with an attached $250 \mu \mathrm{m}$ mesh for pre-filtering of the samples, Winklersuitable, precisely calibrated borosilicate glass bottles of $125 \mathrm{~mL}$ nominal volume (Afora) were first rinsed with water from the corresponding treatment and then filled past the point of overflowing for a few seconds. The lids were carefully placed and each bottle was checked to be bubble free or otherwise be subsampled again. Due to a logistical issue in the supply of the glass bottles, only eight out of nine mesocosms were sampled.

For each treatment/mesocosm a total of 12 measurements were made consisting of fourfold measurements for initial oxygen values fixed with the reagents immediately after subsampling ("Initial"), fourfold 24-h dark incubations ("Dark") and fourfold 24-h light incubations ("Light"), respectively. All samples were stored together in an outdoor pool with constant flow of seawater to keep the incubations at seawater temperature $\left(\sim 20.7-21.5^{\circ} \mathrm{C}\right)$ and exposed to ambient day and night cycles. Initials were stored in the same pool too and covered with opaque material to block sunlight. Dark samples were incubated in light proof bags inside opaque boxes. Light samples were randomly distributed inside clear Plexiglas boxes and covered with one layer of blue foil to better mimic the light spectrum of the water column inside the mesocosms (172 Lagoon Blue foil, Lee filters, Burbank, CA, United States). The mean daily light irradiance received by the light incubations was approx. $22.4 \pm 8.8 \mu \mathrm{mol}$ photons $\mathrm{m}^{-2} \mathrm{~s}^{-1}$ during the duration of the experiment as measured by data loggers inside the incubators (HOBO UA-00264, Australia/New Zealand). 
Dark samples were incubated for at least $20 \mathrm{~h}$ and light samples for $24 \mathrm{~h}$ before being fixed and titrated during $\sim 3 \mathrm{~min}$ by means of an automated, precise titration system with colorimetric end-point detection along with the initials (Williams and Jenkinson, 1982). The precision achieved in replicates was $\% \mathrm{CV}<0.07$. The mean of each fourfold measurement was calculated and used for determining the rates for community respiration (CR), net community production $(\mathrm{NCP})$ and gross production (GP) as follows:

$$
\begin{gathered}
\mathrm{CR}\left[\mu \mathrm{mol} \mathrm{L}^{-1} \mathrm{~h}^{-1}\right]=\frac{\text { Conc }_{\mathrm{I}}-\text { Conc }_{\mathrm{D}}}{\mathrm{h}_{\mathrm{D}}} \\
\mathrm{NCP}\left[\mu \mathrm{mol} \mathrm{L}^{-1} \mathrm{~h}^{-1}\right]=\frac{\text { Conc }_{\mathrm{L}}-\mathrm{Conc}_{\mathrm{I}}}{\mathrm{h}_{\mathrm{L}}} \\
\mathrm{GP}\left[\mu \mathrm{mol} \mathrm{L}^{-1} \mathrm{~h}^{-1}\right]=\mathrm{CR}+\mathrm{NCP}
\end{gathered}
$$

Conc $_{\mathrm{I}} /$ Conc $_{\mathrm{D}} /$ Conc $_{\mathrm{L}}=$ mean oxygen concentration of the Initial / Dark / Light samples;

$h_{D} / h_{L}=$ hours of incubation of Dark / Light samples; CR, $\mathrm{NCP}$ and GP in $\left[\mu \mathrm{mol} \mathrm{L}^{-1} \mathrm{~h}^{-1}\right]$.

Hourly rates were then multiplied by 24 to yield daily rates. Assessment of accumulated NCP $\left(\mathrm{NCP}_{\text {cum }}\right)$ over all 37 days required estimates of oxygen production rates for non-sampling days. The mean NCP of the day before and after each nonsampling day was calculated according to Equation 4 to account for this (e.g., estimated NCP for $\mathrm{d} 22$ was the mean NCP from $\mathrm{d} 21$ and $\mathrm{d} 23$ ).

$$
\mathrm{NCP}_{\mathrm{nsd}}=\frac{\mathrm{NCP}_{\mathrm{nsd}-1}+\mathrm{NCP}_{\mathrm{nsd}+1}}{2}
$$

where $\mathrm{NCP}_{\text {nsd }}=\mathrm{NCP}$ of the non-sampling day and $\mathrm{NCP}_{\text {nsd }-1 /+1}=\mathrm{NCP}$ of the sampling day before / after the non-sampling day. With non-sampling days accounted for, $\mathrm{NCP}_{\text {cum }}$ for a given day could be calculated by summing up the $\mathrm{NCP}$ of all previous days (using $\mathrm{d} 3$ as an example):

$$
\mathrm{NCP}_{\text {cum d } 3}=\mathrm{NCP}_{\mathrm{d} 3}+\mathrm{NCP}_{\mathrm{d} 2}+\mathrm{NCP}_{\mathrm{d} 1}
$$

NCP of all 37 days was then consecutively summed up to estimate $\mathrm{NCP}_{\text {cum }}$ throughout the entire experimental period. This served to better visualize the contrasting developments of the parameter among the treatments (as done similarly by e.g., Engel et al., 2013).

\section{Phytoplankton Community Composition}

Water samples from the IWS were gently filtered on $0.7 \mu \mathrm{m}$ pore size glass fiber filters (200 mbar, Whatman GF/F, Maidstone, United Kingdom) on custom-built filtration manifolds. The filtered volume varied between 0.3 and 1 liter since it had to be adapted to the abundance of plankton in the mesocosms every sampling day to avoid clogging and long filtration times that could affect sample quality. Precautions were also taken to minimize the exposure of the samples to light (e.g., covering filtration manifolds). Afterward filters were shock frozen in liquid nitrogen before being stored in a $-80^{\circ} \mathrm{C}$ freezer until the end of the experiment.
Before analysis samples were mixed with $0.5 \mathrm{~mm}$ glass beads and $1.3 \mathrm{ml}$ of 100\% HPLC grade acetone (Baker 8142, Avantor, Radnor, PA, United States) and extracted in a homogenizer (Precellys, Montigny-le-Bretonneux, France). They were then centrifuged (10 $\mathrm{min}, 4^{\circ} \mathrm{C}, 10,000 \mathrm{rpm}$ ), the supernatant removed with a syringe and filtered through a PTFE filter $(0.2 \mu \mathrm{m}$ pore size). All relevant photosynthetic pigments were analyzed through reverse-phase high-performance liquid chromatography (HPLC, according to Van Heukelem and Thomas, 2001) on a Thermo Scientific HPLC Ultimate 3000.

Determination of the relative abundance of different phytoplankton classes was conducted with the CHEMTAX software developed by Mackey et al. (1996) and applying pigment ratios typically found in the waters off Gran Canaria (Taucher et al., 2018). By calculating the ratios between classspecific pigments and total Chla $[\mathrm{ng} / \mathrm{l}]$ the software determines the individual contribution of Prasinophyceae, Chlorophyceae, Dinophyceae, Cryptophyceae, Chrysophyceae, Prymnesiophyceae, Prochlorophyceae, Cyanophyceae and Diatomea to total Chla. Additional identification of diatom species and abundances was carried out through microscopy counts and size measurements, followed by biovolume calculations and conversion to biomass using the conversion factor from Menden-Deuer and Lessard (2000).

\section{Data Analysis}

Simple linear regressions were performed on the mean NCP/GP/CR datasets to assess the relationship between increasing UI and increasing $\mathrm{NCP} / \mathrm{GP} / \mathrm{CR}$, and to check for differences between both upwelling modes. The control treatment was used twice in the linear regression model analysis of singular and recurring treatments respectively. Statistical comparison of both upwelling modes required the control to be removed, since using the same control for both groups would create a paired data-point in otherwise unpaired data. Data analysis was performed with $\mathrm{R}$ (Version 4.0.3, packages stats, ggplot2; The R Foundation). Assumptions of normality and homoscedasticity were tested using $\mathrm{q}-\mathrm{q}$ and residual vs. fitted variable plots.

\section{RESULTS}

\section{Inorganic Nutrients}

Nutrient concentration peaks were visible in all treatments in proportion to simulated upwelling intensity after the first DW addition (Figure 1). In singular treatments, all nutrients were almost entirely consumed within 5 days (by d9), while recurring treatments exhausted most nutrients within 2 days after each addition. The only exceptions were silicate, which was no longer fully taken up after d27 in extreme recurring, and ammonia, which fluctuated around relatively constant levels in most treatments throughout the experiment.

\section{Oxygen Production and Metabolic Balance}

Following the first DW addition, NCP rates increased in all treatments according to upwelling intensity, though duration 


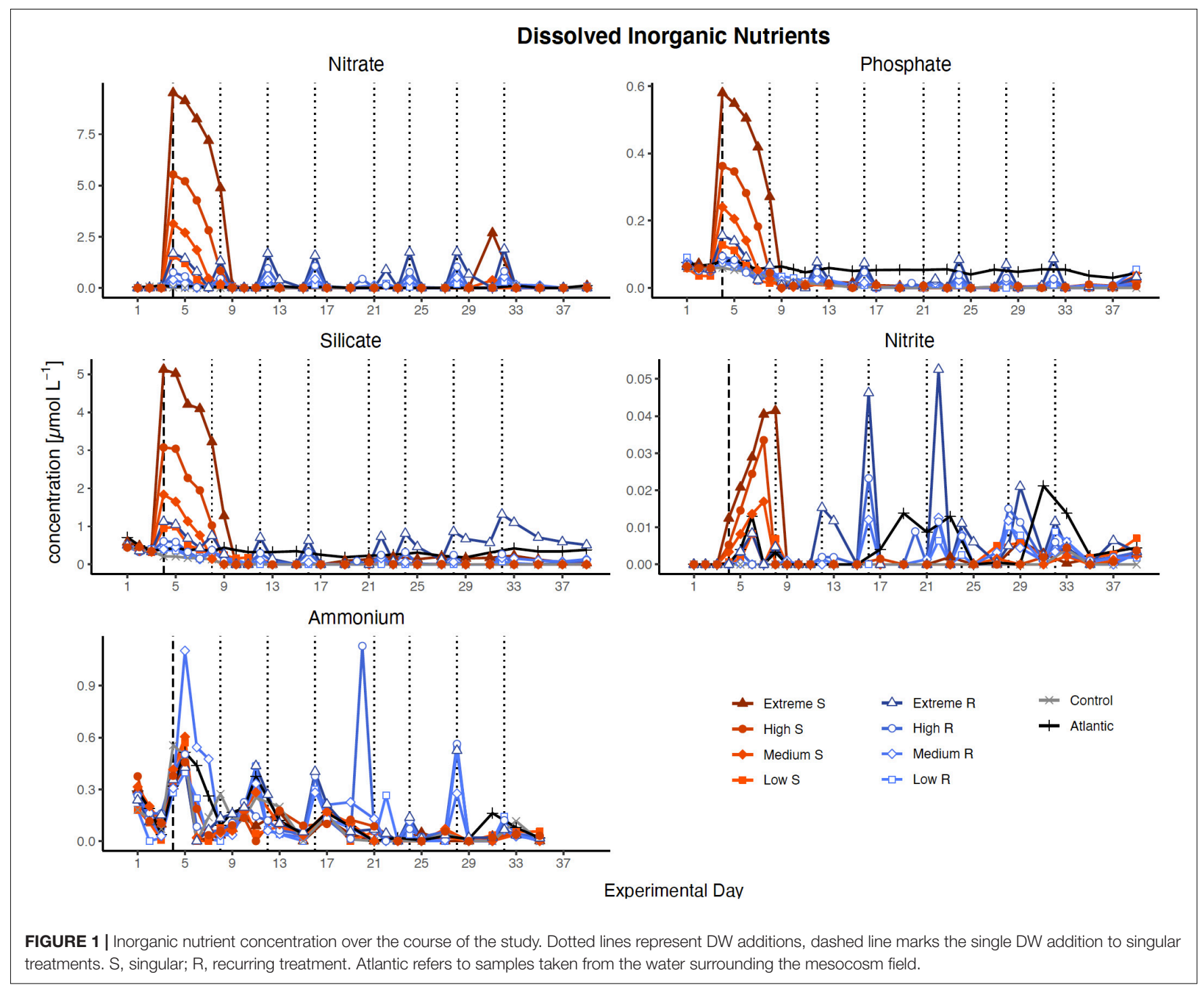

of the increase and peak rates varied substantially (Figure 2A). Singular treatment NCP increased up to $61.52 \mathrm{O}_{2} \mathrm{~L}^{-1} \mathrm{~d}^{-1}$ (extreme) before dropping to levels close to the control. Following nutrient depletion, NCP in all singular treatments dropped to control values close to 0 , and the extreme singular even maintained negative (i.e., net heterotrophic) NCP rates until the end of the experiment. Recurring treatments on the other hand retained entirely positive (i.e., net autotrophic) NCP rates after treatment initiation with the exception of the low recurring. Accumulated NCP rates highlighted this particular difference between both treatment groups (Figure 2D). Recurring treatments exhibited a steady increase (except low) while the singular treatments stagnated or even began dropping, to the point that extreme recurring surpassed the $\mathrm{NCP}_{\text {cum }}$ of extreme singular on d24. Ultimately, it outperformed extreme singular by a factor of 2.7. Gross production was similarly enhanced, with extreme recurring outperforming extreme singular by a factor of 1.6 (Figure 2B). The temporal development of the ratio of GP and respiration was also akin to that of
NCP (Figure 2C). Extreme recurring in particular displayed an increase in all productivity measures toward the end of the experiment, even reaching the highest overall GP at $31.94 \mu \mathrm{mol}$ $\mathrm{O}_{2} \mathrm{~L}^{-1} \mathrm{~d}^{-1}$ on $\mathrm{d} 35$. Mean NCP rates calculated for the duration of the experiment showed that recurring upwelling led to higher mean NCP than singular, with the extreme recurring reaching a three times higher mean NCP despite receiving only 1.2 times as many nutrients as the extreme singular (Figure $\mathbf{3}$ and Table 1). Mean NCP, GP and CR all strongly correlated with upwelling intensity under both upwelling modes (Table 2). However, recurring upwelling led to significantly higher mean NCP and GP than singular. Chla normalized NCP rates were not influenced much by upwelling intensity, but rather by upwelling mode (Supplementary Figure 2): following an initial peak (2.19$\left.8.68 \mu \mathrm{mol} \mathrm{O}_{2}(\mu \mathrm{g} \mathrm{Chla}) \mathrm{d}^{-1}\right)$ in all treatments after upwelling onset, singular treatments dropped to rates between -3 and $1.1 \mu \mathrm{mol} \mathrm{O}_{2}(\mu \mathrm{g} \mathrm{Chla}) \mathrm{d}^{-1}$ under low and medium intensity, while the extreme upwelling intensity oscillated as far as $-9 \mu \mathrm{mol}$ $\mathrm{O}_{2}(\mu \mathrm{g} \mathrm{Chla}) \mathrm{d}^{-1}$ on $\mathrm{d} 31$. Contrary to this, recurring treatments 


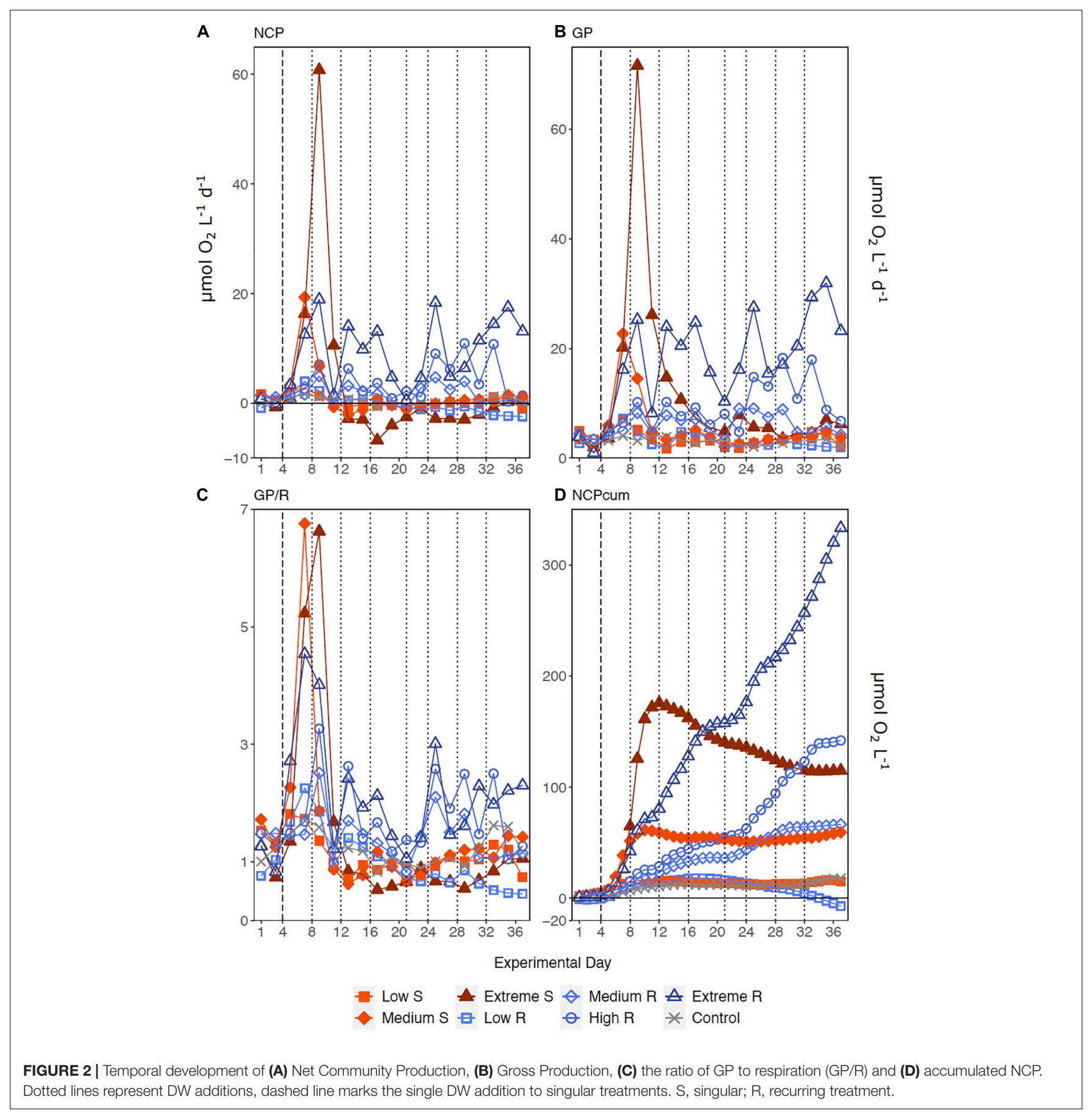

of medium, high and extreme intensity mostly retained rates between 0 and $4.7 \mu \mathrm{mol} \mathrm{O}_{2}(\mu \mathrm{g} \mathrm{Chl} a) \mathrm{d}^{-1}$. With the low recurring treatment again representing the exception, dropping down as far as $-11 \mu \mathrm{mol} \mathrm{O} \mathrm{O}_{2}(\mu \mathrm{g} \mathrm{Chl} a) \mathrm{d}^{-1}$ toward the end of the experiment.

\section{Phytoplankton Community Composition}

Low treatments developed similarly to the control throughout the experiment, showing constant shifts in relative class abundances though diatoms mostly represented the largest proportion
(Figure 4). But strong differences were present regarding the timing and magnitude of diatom prevalence: after the DW addition, all singular treatments developed strong initial Chla peaks dominated by diatoms and, to a lesser extent by prymnesiophytes. In general, diatoms remained the class with the highest contribution to total Chla in singular treatments, also following the overall decrease in Chla and productivity during the course of the experiment. Recurring treatments were highly dominated by diatoms throughout the experiment albeit the magnitude of Chla increase was smaller. Prymnesiophyte 


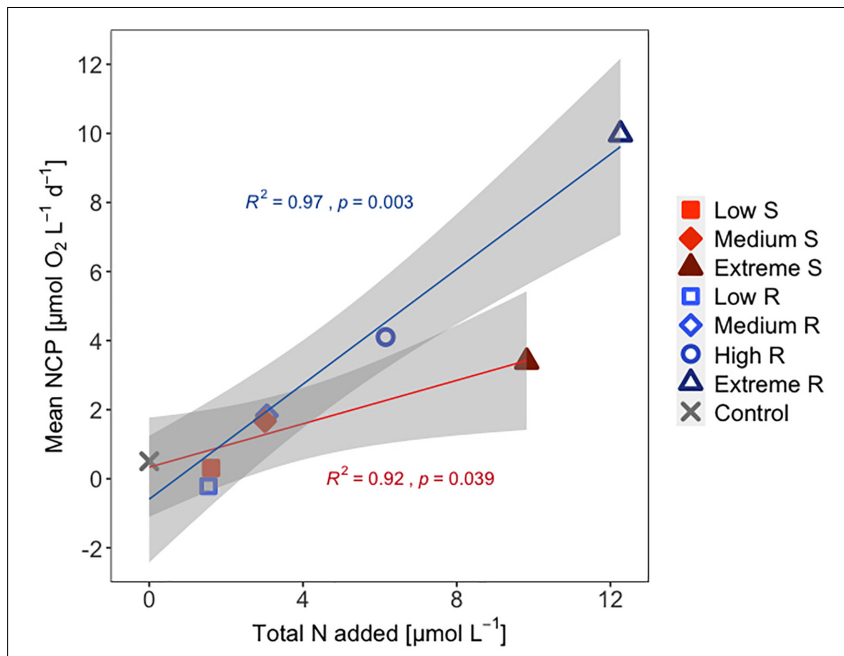

FIGURE 3 | Mean NCP [ $\mu \mathrm{mol} \mathrm{O} \mathrm{L}^{-1} \mathrm{~d}^{-1}$ ] of each treatment vs. amount of inorganic $\mathrm{N}$ added $\left[\mu \mathrm{mol} \mathrm{L}{ }^{-1}\right]$. S, singular; $\mathrm{R}$, recurring treatment. Shaded area shows the $95 \%$ confidence interval. $R^{2}$ - and $p$-values shown for the linear regression line of each upwelling mode + control.

relative abundance increased slightly with upwelling intensity toward the end, particularly in the extreme recurring. Overall, there was a visible reaction pattern to DW additions in all recurring treatments except the low. Under both upwelling modes, Chla showed a strong positive correlation with upwelling intensity (Table 2).

In contrast to all treated mesocosms, the Atlantic maintained an overall low concentration of $\mathrm{Chl} a$, rarely rising above $0.3 \mu \mathrm{g} \mathrm{L}^{-1}$, and displayed a variable phytoplankton community composition with a very low contribution of diatoms. Additional diatom biomass calculations based on taxonomic identification and size measurements through microscopy revealed no pronounced species composition differences between treatments. Relative Biomass contribution in all treatments and the control was at least $\sim 25 \%$ from Leptocylindrus danicus followed by Guinardia striata in the singular and G. striata and Leptocylindrus minimus in the recurring treatments. Chaetoceros $s p$. contributed approx. $10-15 \%$ biomass in all mesocosms (Supplementary Figure 3 and Table 1).

\section{DISCUSSION}

\section{Phytoplankton Community Responses to Artificial Upwelling}

The results presented require an interpretation of singular and recurring upwelling modes by themselves as well as a comparison of both. Regarding the former, i.e., within each upwelling mode, the results are in line with what we expected from an oligotrophic system reacting to nutrient input: GP, NCP and Chla peaks scaled with upwelling intensity (Figures 2, 4). While singular treatments only displayed one peak after the DW addition, an increase in GP and NCP was visible after each addition in the high and extreme recurring treatments. The
TABLE 2 | Linear regressions statistics of the relationship between productivity parameters (NCP, GP, CR, Chla) vs. upwelling intensity and for differences between upwelling modes.

\begin{tabular}{lccc}
\hline Parameter & $\boldsymbol{F}$ statistic & $\boldsymbol{R}^{\mathbf{2}}$ & $\boldsymbol{p}$-value \\
\hline Singular mean NCP vs. $\mu \mathrm{mol} \mathrm{N} \mathrm{L}^{-1}$ & 23.79 & 0.92 & $\mathbf{0 . 0 3 9}$ \\
Singular mean GP vs. $\mu \mathrm{mol} \mathrm{N} \mathrm{L}^{-1}$ & 170.7 & 0.99 & $\mathbf{0 . 0 0 6}$ \\
Singular mean CR vs. $\mu \mathrm{mol} \mathrm{N} \mathrm{L}{ }^{-1}$ & 192.2 & 0.99 & $\mathbf{0 . 0 0 5}$ \\
Singular mean Chla vs. $\mu \mathrm{mol} \mathrm{N} \mathrm{L}^{-1}$ & 300.8 & 0.99 & $\mathbf{0 . 0 0 3}$ \\
Recurring mean NCP vs. $\mu \mathrm{mol} \mathrm{N} \mathrm{L}^{-1}$ & 83.08 & 0.97 & $\mathbf{0 . 0 0 3}$ \\
Recurring mean GP vs. $\mu \mathrm{mol} \mathrm{N} \mathrm{L}^{-1}$ & 176.7 & 0.98 & $<\mathbf{0 . 0 0 1}$ \\
Recurring mean CR vs. $\mu \mathrm{mol} \mathrm{N} \mathrm{L}^{-1}$ & 301.6 & 0.99 & $\mathbf{0 . 0 0 1}$ \\
Recurring mean Chla vs. $\mu \mathrm{mol} \mathrm{N} \mathrm{L}^{-1}$ & 140.4 & 0.98 & $\mathbf{0 . 0 0 1}$ \\
mean NCPsingular vs. mean NCPrecurring & 105.2 & 0.99 & $\mathbf{0 . 0 0 8}$ \\
mean GPsingular vs. mean GPrecurring & 210.1 & 0.99 & $\mathbf{0 . 0 3}$ \\
mean CRingular vs. mean CRrecurring & 119.4 & 0.99 & 0.114 \\
mean Chlasingular vs. mean Chlarecurring & 318.1 & 0.99 & 0.175
\end{tabular}

Statistically significant correlations / differences are highlighted in bold.

same pattern was visible in the Chla concentration of medium recurring as well. The strong positive response of all variables to increasing upwelling intensity was corroborated by the linear regression analysis for both upwelling modes (Table 2). The observed shift to a dominance of diatoms in all treatments (Figure 4) is also coherent with earlier studies: Phytoplankton community analysis from mesocosms, upwelling filaments, eddies and oligotrophic areas within the Canary Islands region have consistently shown the same succession patterns. There is a consistent shift from small picophytoplankton under nutrient depleted to larger microphytoplankton, and predominantly diatoms, under nutrient replete conditions. This is valid for both, nutrient-enriched water bodies (e.g., eddies or mesocosm experiments) (Mann, 1993; Arístegui and Montero, 2005; Fawcett and Ward, 2011; Taucher et al., 2017) as well as for transects following filaments from (oligotrophic) offshore to (eutrophic) coastal upwelling areas (Arístegui et al., 2004). Additionally, Ferreira et al. (2020) found that nutrient pulses in a microcosm experiment led to similar community composition changes. Interestingly, from the three largest contributors to diatom biomass, Leptocylindrus danicus and L. minimus were also found to be by far the most abundant in a previous mesocosm study with nutrient fertilization at the same geographical location (Taucher et al., 2018). The development of phytoplankton size and composition is somewhat contrary to what Masuda et al. (2010) found in their study: Despite Nitrate concentrations of $4.6 \mu \mathrm{M}$ in the discharged water, they reported active growth of pico- and nanophytoplankton (particularly Cryptophytes and Synechococcus), but not diatoms. They attributed this to low light availability at discharge depth $(6 \pm 3 \%)$ compared to the surface layer combined with poor shade adaptation of surface populations $(5 \mathrm{~m})$ mixed into the discharge depth $(20 \mathrm{~m})$, visible as a lack of photosynthetic pigment increase. Low light availability was not an issue in our experiment that hence provided better growing conditions for diatoms. Similarly, Maruyama et al. (2011) measured far higher peak Chla concentrations than we found (up to $\sim 30 \mu \mathrm{g} \mathrm{L}^{-1}$ ), 


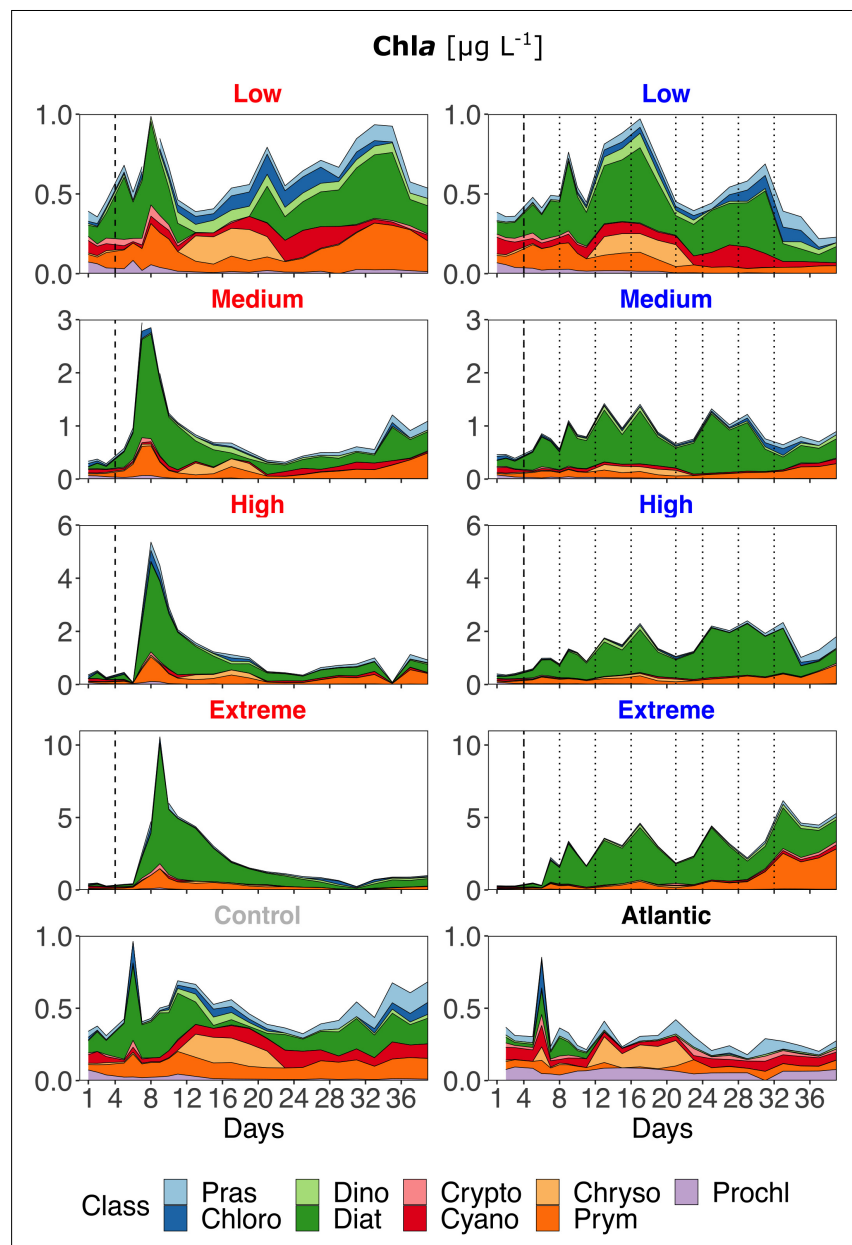

FIGURE 4 | Contribution of each phytoplankton class to total Chla based on Chemtax analysis of photosynthetic pigments (HPLC). Note the different y-axis scales. Abbreviations stand for: Prasinophyceae, Chlorophyceae, Dinophyceae, Cryptophyceae, Chrysophyceae, Prymnesiophyceae, Prochlorophyceae, Cyanophyceae, and Diatomea. Atlantic refers to samples taken from the water surrounding the mesocosm field. Dotted lines represent DW additions, dashed line marks the single DW addition to singular treatments. Red labels represent singular and blue labels recurring treatments.

the explanation for this being that they measured $\mathrm{Chl} a$ concentrations in the top surface layer close to the output of the upwelling pump. Our samples were integrated over $15 \mathrm{~m}$ of water column and still showed peak Chla concentrations of up to $\sim 10 \mu \mathrm{g} \mathrm{L}^{-1}$, with the high and extreme recurring treatments constantly maintaining concentrations between 1 and $5 \mu \mathrm{g} \mathrm{L}^{-1}$.

Inorganic nutrients were generally consumed entirely and quickly. It took the phytoplankton in the singular treatments a few days after the initial DW addition and once the phytoplankton community in the recurring treatments adapted to the input, consumption was immediate and almost absolute (Figure 1). This pattern of fast and complete nutrient uptake is comparable to what has been observed in other studies with simulated upwelling in the same geographical location (Hernández-Hernández et al., 2018; Taucher et al., 2018).
Since these results do not offer a straightforward explanation as to why recurring upwelling significantly outperformed singular upwelling in terms of $\mathrm{NCP}_{\text {cum }}$ and mean $\mathrm{NCP}$ we discuss two points that might have contributed to this disparity and that also make the comparison of both upwelling modes more complex.

\section{Underestimation of Singular Treatment Peaks}

The workload produced by the oxygen measurements only allowed for sampling every second day. Meanwhile, almost the entire period of autotrophy (positive NCP values) in this treatment took place between $\mathrm{d} 7-\mathrm{d} 11$ (Figure 2A). Considering the swiftness and strength of the response in the extreme singular treatment, this might have led to an underestimation of the initial productivity peak. Given that the $\mathrm{NCP}_{\text {cum }}$ of this treatment differed most from its recurring counterpart this is relevant for the interpretation of the data. If NCP peaked on a non-sampling day, the real magnitude of the initial peak might have been higher than we measured. This in turn would affect the temporal development of $\mathrm{NCP}_{\text {cum }}$. To some extent, the high and sudden nutrient input might have led to so called luxury consumption (Droop, 1974) rather than immediate production. But judging by the swiftness of both nutrient consumption and the following GP decrease (Figure 2B), luxury consumption could only have taken place during a short period of time and it does not bar an underestimation of the initial peak. Hence in terms of $\mathrm{NCP}_{\text {cum }}$, there is a chance that particularly the extreme treatments differed less than observed. The stark difference in mean NCP per $\mu \mathrm{mol}$ $\mathrm{N}$ visible in Figure 3 should therefore be interpreted with some caution, not least because it represents a regression run through 4-5 data points. This is also the case for the other linear regression statistics displayed in Table 2. An underestimation of peak values would also provide an explanation to why mean NCP and GP was significantly higher under recurring upwelling compared to singular whereas Chla was not (Table 2), although at least GP and Chla should be closely related.

\section{Different Temporal Evolution of Production and Respiration}

Productivity and respiration happened on different timeframes and magnitudes in each upwelling mode: Singular treatments went through a brief productive phase $(\mathrm{d} 5-\mathrm{d} 11)$ followed by an extended period of low productivity and higher respiration (d12-d37), visible in the consistently low GP/R or negative NCP from day 12 onward (Figures 2A,C). Recurring treatments on the other hand consistently retained a net-autotrophic state after treatment onset. The same trend persisted when normalizing NCP rates to Chla (Supplementary Figure 2). In the singular treatments, this extended phase of a balanced to net-heterotrophic state might also have opened a niche for mixotrophic organisms that could further influence the metabolic balance: microscopic cell counts and flow cytometry showed an increase in dinoflagellate abundance, that followed the singular DW addition and coincided temporally with the ensuing decrease in GP/R 
(Schulz et al., unpublished data). Many of the dinoflagellate genera identified in this experiment are potentially mixotrophic (Supplementary Table 2), a very common physiological trait among dinoflagellates in general (Stoecker, 1999). On the other hand, the constant net autotrophy of the recurring treatments implies that the phytoplankton that capitalized first on nutrient availability succeeded in doing so throughout the experiment (mainly diatoms, followed by Prymnesiophytes toward the end in high and extreme recurring). This is corroborated by a recent modeling study on competition between diatoms and mixotrophic protists that found key diatom traits (phototrophy and vacuolation) to be more advantageous under high nutrient concentration, while mixotroph traits (phototrophy and phagotrophy) succeeded under nutrient limitation (Cadier et al., 2020). The increase in dinoflagellate abundance might also offer an explanation for the overall lower Chla-normalized NCP rates in the singular treatments compared to the recurring.

\section{CONCLUSION}

In summary, our results show that artificial upwelling led to the establishment of a productive, diatom dominated community of primary producers. However, differences in NCP became more pronounced with increasing upwelling intensity. We conclude that the mode in which nutrients are supplied to an oligotrophic system plays a crucial role in how it responds to artificial upwelling.

The results imply that high intensity recurring upwelling might be better suited to increase overall food web productivity (and therefore fishery yields) than singular, as it managed to sustain a net autotrophic community of primary producers that could nurture the rest of the food web. The highest recurring upwelling intensity yielded a three times higher mean NCP compared to the singular despite receiving only 1.25 times as many nutrients, and overall, recurring upwelling led to significantly higher mean NCP and GP compared to singular. This needs to be put into context with higher trophic levels, as well as factors that influence productivity (biomass, grazing, export) to evaluate if high trophic transfer efficiency and/or carbon export was actually achieved. If artificial upwelling is to be applied with a specific purpose (increase of carbon sequestration or food web productivity) we also need to understand why the observed "autotrophic recurring" vs. "heterotrophic singular" scenario developed.

These results highlight the need to consider empirically measured local effects like community structure and metabolism under artificial upwelling. They have major implications not only for future assessments of upwelling impacts, but specifically for imminent policymaker decisions on the potential employment of artificial upwelling as an ocean-based solution.

\section{REFERENCES}

Arístegui, J., and Montero, M. F. (2005). Temporal and spatial changes in plankton respiration and biomass in the Canary Islands region: the effect of mesoscale variability. J. Mar. Syst. 54, 65-82. doi: 10.1016/j.jmarsys.2004.07.004

\section{DATA AVAILABILITY STATEMENT}

The raw data supporting the conclusions of this article will be made available by the authors, without undue reservation. The data will be submitted to Pangaea, https://www.pangaea.de/.

\section{AUTHOR CONTRIBUTIONS}

UR, JA, and JT contributed to experimental concept and design. JO and JA contributed to data analysis. JO wrote the manuscript with input from all co-authors. All authors contributed to the execution of the experiment.

\section{FUNDING}

This project was conducted in the framework of the project Ocean Artificial Upwelling (Ocean art Up) funded by an Advanced Grant of the European Research Council. Additional support was provided through Transnational Access funds by the EU project AQUACOSM, EU H2020-INFRAIA-project No. 731065, and by project TRIATLAS (AMD-817578-5) from the European Union's Horizon 2020 to JA. JA was also supported by a Helmholtz International Fellow Award, 2015 (Helmholtz Association, Germany) as well as Project FONIAC 2019 (Fundación Caja Canarias and Fundación Bancaria La Caixa).

\section{ACKNOWLEDGMENTS}

The authors are grateful to the Oceanic Platform of the Canary Islands (PLOCAN) and its staff for the use of their facilities, and for their hospitality and help with the logistics and organization of this research campaign. The authors would also like to thank the biological oceanography group of the University of Las Palmas de Gran Canaria (GOB-ULPGC) for providing additional lab facilities. Particular thanks go to Minerva Espino and Acorayda González for their valuable contribution to the measurements of primary productivity. The captain and crew of RV James Cook are thanked for deploying the mesocosms and collecting the deep water. Special thanks go to the KOSMOS team of GEOMAR for taking care of all logistical and technical aspects of this mesocosm campaign and for coordinating the research activities on site as well as the data management and exchange.

\section{SUPPLEMENTARY MATERIAL}

The Supplementary Material for this article can be found online at: https://www.frontiersin.org/articles/10.3389/fmars. 2021.743105/full\#supplementary-material

Arístegui, J., Barton, E. D., Tett, P., Montero, M. F., García-Muñoz, M., Basterretxea, G., et al. (2004). Variability in plankton community structure, metabolism, and vertical carbon fluxes along an upwelling filament (Cape Juby, NW Africa). Prog. Oceanogr. 62, 95-113. doi: 10.1016/j.pocean.2004.0 7.004 
Arístegui, J., Hernández-León, S., Montero, M. F., and Gómez, M. (2001). The seasonal planktonic cycle in coastal waters of the Canary Islands. Sci. Mar. 65, 51-58. doi: 10.3989/scimar.2001.65s151

Bryan, J. R., Rlley, J. P., and Williams, P. J. L. (1976). A winkler procedure for making precise measurements of oxygen concentration for productivity and related studies. J. Exp. Mar. Bio. Ecol. 21, 191-197. doi: 10.1016/0022-0981(76) 90114-3

Cadier, M., Hansen, A. N., Andersen, K. H., and Visser, A. W. (2020). Competition between vacuolated and mixotrophic unicellular plankton. J. Plankton Res. 42, 425-439. doi: 10.1093/plankt/fbaa025

Carritt, D. E., and Carpenter, J. H. (1966). Comparison and evaluation of currently employed modifications of the Winkler method for determining dissolved oxygen in seawater; a NASCO report. J. Mar. Res. 24, 286-318.

Casareto, B. E., Niraula, M. P., and Suzuki, Y. (2017). Marine planktonic ecosystem dynamics in an artificial upwelling area of Japan: phytoplankton production and biomass fate. J. Exp. Mar. Bio. Ecol. 487, 1-10. doi: 10.1016/j.jembe.2016.11.002

Droop, M. R. (1974). The nutrient status of algal cells in continuous culture. J. Mar. Biol. Assoc. U. K. 54, 825-855. doi: 10.1017/S002531540005760X

Engel, A., Borchard, C., Piontek, J., Schulz, K. G., Riebesell, U., and Bellerby, R. (2013). CO2 increases $14 \mathrm{C}$ primary production in an Arctic plankton community. Biogeosciences 10, 1291-1308. doi: 10.5194/bg-10-1291-2013

Fawcett, S. E., and Ward, B. B. (2011). Phytoplankton succession and nitrogen utilization during the development of an upwelling bloom. Mar. Ecol. Prog. Ser. 428, 13-31. doi: 10.3354/meps09070

Ferreira, A., Sá, C., Silva, N., Beltrán, C., Dias, A. M., and Brito, A. C. (2020). Phytoplankton response to nutrient pulses in an upwelling system assessed through a microcosm experiment (Algarrobo Bay, Chile). Ocean Coast. Manag. 190:105167. doi: 10.1016/j.ocecoaman.2020.105167

Garcia, S. M., and Rosenberg, A. A. (2010). Food security and marine capture fisheries: Characteristics, trends, drivers and future perspectives. Philos. Trans. R. Soc. B Biol. Sci. 365, 2869-2880. doi: 10.1098/rstb.2010.0171

GESAMP (2019). High level review of a wide range of proposed marine geoengineering techniques. GESAMP Rep. Stud. 144. Available online at: http://www.gesamp.org/publications/high-level-review-of-a-wide-range- ofproposed-marine-geoengineering-techniques (accessed December 6, 2021).

Giraud, M., Boye, M., Garçon, V., Donval, A., and de la Broise, D. (2016). Simulation of an artificial upwelling using immersed in situ phytoplankton microcosms. J. Exp. Mar. Bio. Ecol. 475, 80-88. doi: 10.1016/j.jembe.2015.1 1.006

Godfray, H. C. J., Crute, I. R., Haddad, L., Muir, J. F., Nisbett, N., Lawrence, D., et al. (2010). The future of the global food system. Philos. Trans. R. Soc. B Biol. Sci. 365, 2769-2777. doi: 10.1098/rstb.2010.0180

Grasshoff, K., Kremling, K., and Ehrhardt, M. (1999). Methods of Seawater Analysis. Chapter 4: Determination of Oxygen, Vol. 3. Weinheim: Wiley-VCH.

Hernández-Hernández, N., Bach, L. T., Montero, M. F., Taucher, J., Baños, I., Guan, W., et al. (2018). High CO 2 under nutrient fertilization increases primary production and biomass in subtropical phytoplankton communities: a mesocosm approach. Front. Mar. Sci. 5:213. doi: 10.3389/fmars.2018.00213

Kirke, B. (2003). Enhancing fish stocks with wave-powered artificial upwelling. Ocean Coast. Manag. 46, 901-915. doi: 10.1016/S0964-5691(03)00067-X

Lawrence, M. G., Schäfer, S., Muri, H., Scott, V., Oschlies, A., Vaughan, N. E., et al. (2018). Evaluating climate geoengineering proposals in the context of the Paris Agreement temperature goals. Nat. Commun. 9:5938. doi: 10.1038/s41467-01805938-3

Lovelock, J. E., and Rapley, C. G. (2007). Ocean pipes could help the Earth to cure itself. Nature 449:2007.

Mackey, M. D., Mackey, D. J., Higgins, H. W., and Wright, S. W. (1996). CHEMTAX - A program for estimating class abundances from chemical markers: application to HPLC measurements of phytoplankton. Mar. Ecol. Prog. Ser. 144, 265-283. doi: 10.3354/meps144265

Mann, K. H. (1993). Physical oceanography, food chains, and fish stocks: a review. ICES J. Mar. Sci. 50, 105-119. doi: 10.1006/jmsc.1993.1013

Maruyama, S., Yabuki, T., Sato, T., Tsubaki, K., Komiya, A., Watanabe, M., et al. (2011). Evidences of increasing primary production in the ocean by Stommel's perpetual salt fountain. Deep. Res. Part I Oceanogr. Res. Pap. 58, 567-574. doi: 10.1016/j.dsr.2011.02.012

Masuda, T., Furuya, K., Kohashi, N., Sato, M., Takeda, S., Uchiyama, M., et al. (2010). Lagrangian observation of phytoplankton dynamics at an artificially enriched subsurface water in Sagami Bay. Japan. J. Oceanogr. 66, 801-813. doi: 10.1007/s10872-010-0065-1

McAndrew, P. M., Björkman, K. M., Church, M. J., Morris, P. J., Jachowski, N., Williams, P. J. L. B., et al. (2007). Metabolic response of oligotrophic plankton communities to deep water nutrient enrichment. Mar. Ecol. Prog. Ser. 332, 63-75. doi: 10.3354/meps332063

Menden-Deuer, S., and Lessard, E. J. (2000). Carbon to volume relationships for dinoflagellates, diatoms, and other protist plankton. Limnol. Oceanogr. 45, 569-579. doi: 10.4319/lo.2000.45.3.0569

Riebesell, U., Gattuso, J. P., Thingstad, T. F., and Middelburg, J. J. (2013b). Arctic ocean acidification: Pelagic ecosystem and biogeochemical responses during a mesocosm study. Biogeosciences 10, 5619-5626. doi: 10.5194/bg-10-561 9-2013

Riebesell, U., Czerny, J., Von Bröckel, K., Boxhammer, T., Büdenbender, J., Deckelnick, M., et al. (2013a). Technical note: a mobile sea-going mesocosm system - new opportunities for ocean change research. Biogeosciences 10, 1835-1847. doi: 10.5194/bg-10-1835-2013

Schellnhuber, H. J., Rahmstorf, S., and Winkelmann, R. (2016). Why the right climate target was agreed in Paris. Nat. Clim. Chang. 6, 649-653. doi: 10.1038/ nclimate 3013

Stoecker, D. K. (1999). Mixotrophy among dinoflagellates. J. Eukaryot. Microbiol. 46, 397-401. doi: 10.1111/j.1550-7408.1999.tb04619.x

Taucher, J., Arístegui, J., Bach, L. T., Guan, W., Montero, M. F., Nauendorf, A., et al. (2018). Response of subtropical phytoplankton communities to ocean acidification under oligotrophic conditions and during nutrient fertilization. Front. Mar. Sci. 5:330. doi: 10.3389/fmars.2018.00330

Taucher, J., Bach, L. T., Boxhammer, T., Nauendorf, A., Achterberg, E. P., AlgueróMuñiz, M., et al. (2017). Influence of ocean acidification and deep water upwelling on oligotrophic plankton communities in the subtropical North Atlantic: insights from an in situ mesocosm study. Front. Mar. Sci. 4:85. doi: $10.3389 /$ fmars.2017.00085

UNFCC (2015). Adoption of the Paris Agreement. Available online at: https:// unfccc.int/documents/9064 (accessed December 6, 2021).

United Nations (2019). World Population Prospects 2019: Highlights (ST/ESA/SER.A/423). Available online at: https://population.un.org/wpp/ Publications/Files/WPP2019_Highlights.pdf (accessed December 6, 2021).

Van Heukelem, L., and Thomas, C. S. (2001). Computer-assisted high-performance liquid chromatography method development with applications to the isolation and analysis of phytoplankton pigments. J. Chromatogr. A 910, 31-49.

Williams, P. J., and Jenkinson, N. W. (1982). A transportable microprocessorcontrolled precise Winkler titration suitable for field station and shipboard use. Limnol. Oceanogr. 27, 576-584. doi: 10.4319/lo.1982.27.3. 0576

Conflict of Interest: The authors declare that the research was conducted in the absence of any commercial or financial relationships that could be construed as a potential conflict of interest.

Publisher's Note: All claims expressed in this article are solely those of the authors and do not necessarily represent those of their affiliated organizations, or those of the publisher, the editors and the reviewers. Any product that may be evaluated in this article, or claim that may be made by its manufacturer, is not guaranteed or endorsed by the publisher.

Copyright (c) 2022 Ortiz, Arístegui, Taucher and Riebesell. This is an open-access article distributed under the terms of the Creative Commons Attribution License (CC BY). The use, distribution or reproduction in other forums is permitted, provided the original author(s) and the copyright owner(s) are credited and that the original publication in this journal is cited, in accordance with accepted academic practice. No use, distribution or reproduction is permitted which does not comply with these terms. 